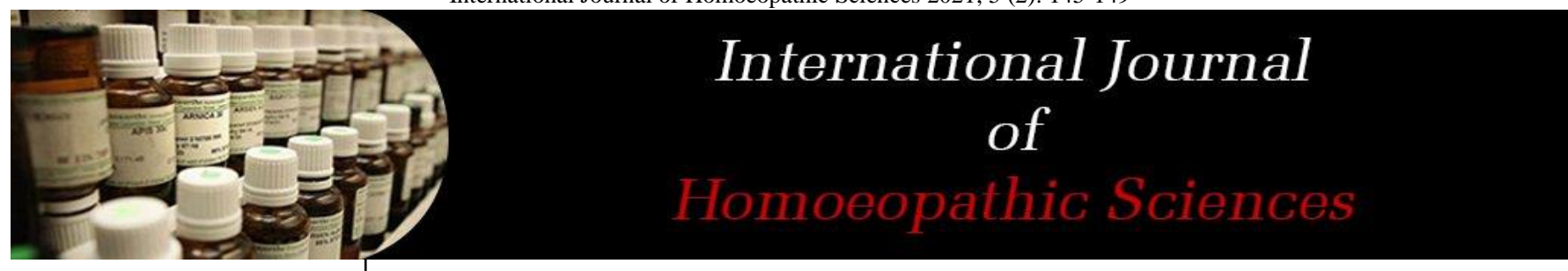

E-ISSN: $2616-4493$ P-ISSN: 2616-4485 www.homoeopathicjournal.com IJHS 2021; 5 (2): 145-149 Received: 07-01-2021 Accepted: 09-02-2021

Khan Sheeba Saleem Post Graduate Trainee Dept. of Case Taking and Repertory, National Institute of Homoeopathy Govt. of West Bengal, India
Corresponding Author: Khan Sheeba Saleem Post Graduate Trainee Dept. of Case Taking and Repertory, National Institute of Homoeopathy Govt. of West Bengal, India

\title{
Homoeopathic treatment of fibroadenoma breast: A case report
}

Khan Sheeba Saleem

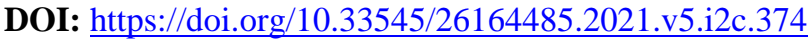

\section{Abstract}

Fibroadenoma is the most common benign tumor occurring in young to middle aged women which disappear after the menopause. Though few cases remain asymptomatic throughout, but the tumor may progress to carcinoma. The conventional treatment includes surgical excision and cryoblation [1]. Symptomatic treatment through homoeopathy can be effective as seen in previous studies ${ }^{[2,3]}$. In this case report, a female aged 33 years of age suffering from fibroadenoma breast, diagnosed in 2015 is given constitutional homoeopathic treatment. After three months of treatment the sonographic report shows normal findings.

Keywords: Fibroadenoma, homoeopathy, breast lump, benign, malignant

\section{Introduction}

Fibroadenoma is a common benign neoplasm, which occurs most frequently in young women. The typical fibroadenoma is round or ovoid, rubbery in consistency, discrete, relatively movable, non-tender mass, $1-5 \mathrm{~cm}$ in diameter ${ }^{[1]}$. It usually occurs after puberty, within 20 years of age and often an accidental finding while clinical examination ${ }^{[4]}$. On examination, fibroadenoma breast is felt as a freely mobile lump with a round smooth margin with a firm consistency except in cases of large intracanalicular variety in which it could be softer ${ }^{[5]}$. The examination of the breast should be included in any case of neck and axillary lymphadenopathy for symmetry, ulcers, redness, peau d'orange appearance, dimpling of skin and nipple discharge to rule out malignancy ${ }^{[6]}$. There is a general agreement that fibroeodenoma is associated with a certain increase in breast cancer risk. The cumulative risk of invasive breast cancer was $0.7 \%$ after 5 years and $2.2 \%$ after 12 years following diagnosis of fibroadenoma ${ }^{[7]}$. Early diagnosis with regular monitoring through clinical examination can help prevent the formation of malignancy.

There are four types of fibroadenoma mentioned as following: ${ }^{[8]}$

- Complex Fibroadenoma: Rapidly growing hyperplastic cells. Diagnosis is confirmed by biopsy of breast tissue. In a cohort study, ${ }^{[9]}$ it was shown that patients with complex fibroadenoma are more likely to suffer from high risk histologic characteristics of breast involution i.e., Incomplete involution and proliferative disease without atypia (PDWA).

- Juvenile Fibroadenoma: This fibroadenoma is commonly found in patients between the age group of 10 to 18 years. The growth rate is faster and they disappear consequently [10]

- Giant Fibroadenoma: This non-cancerous lesion is larger than other types. As the name suggest it is so giant that it replaces normal breast tissue. Usually, a fibroadenoma more than $5 \mathrm{~cm}$ comes under this category. This is one of the rare variety of fibroadenoma in which rapid peak of growth occurs at late adolescence age ${ }^{[11]}$.

- Phyllodes Tumor: A stromal tumor of the breast that can be either benign or malignant. Though, women of any age may fall prey to this pre-cancerous growth, but those between 35-55 years are commonly involved ${ }^{[12]}$.

- The diagnosis of fibroadenoma is confirmed by the appearance of hypoechoic and homogeneous echotexture in sonography ${ }^{[13]}$.

Clinical observation and regular monitoring for 2 to 3 months for fibroadenoma breast contributes to the conservative management of the tumor. Any change in the tumor in terms of colour or growth requires further investigation through sonography and FNAC ${ }^{[15]}$. During the treatment of Breast tumor, the recovery can be assessed by monitoring pain through Visual analogue scale (VAS) ${ }^{[16]}$. 


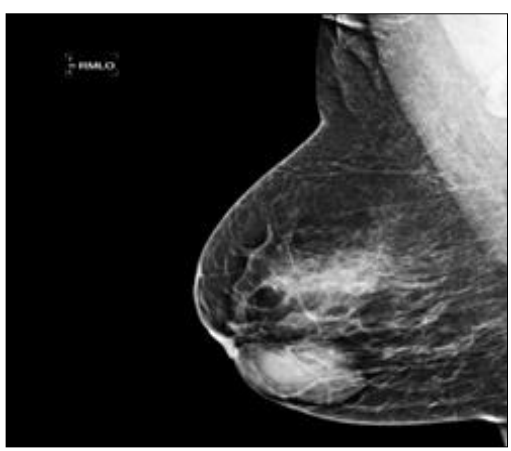

Fig 1: Sonographic impression of Fibroadenoma Breast ${ }^{[14]}$

Previous researches have been conducted by homoeopaths with the evidence of successful homoeopathic treatment in case of fibroadenoma breast and other benign lesions. In a Case report ${ }^{[3]}$, a simple fibroadenoma $(3.48 \times 2.38 \mathrm{~cm})$ confirmed by sono-mammography and FNAC, in an 18 year old girl was treated by individualized medicine Pulsatilla nigricans. An open label, single arm, observational trial ${ }^{[17]}$ was conducted on 23 cases with a significant reduction in mean size $(P<0.001)$ after homoeopathic treatment. In this case report, after a no relief with Bryonia, careful repertorisation was done and Phosphorus was given as an individualized homoepathic prescription. In previous studies also, Phosphorus proved to have a significant role in cancer metabolism, and breast cancer in particular ${ }^{[18]}$.

\section{Case proper}

A female aged 33 years residing in 24 Parganas, visited the NIH OPD on 3rd December, 2018 with the complain of pain in left breast since three years which used to get worse by motion and touch. She also complained of flatulence after meals, especially after eating fatty food.

Patient noticed slight pain in left breast 3 years back while dressing and noticed a lump which was painful on touch and motion. Pain gradually increased in size and on ultrasound fibroadenoma left breast was diagnosed in 2015.

Her Past history revealed nothing significant. Her Mother had hypertension and stroke, Father had Diabetes mellitus, and elder sister had Hypertension. Her Menstrual cycle was regular with a duration of three to four days and experienced occasional dysmenorrhea before and during first two days of the onset of menstrual cycle. There was no complain of discharge per vagina otherwise. She was married since 9 years with one male child (8 years) and one female child (6 years) with no history of miscarriage.

\section{Physical generals}

Thermal reaction was chilly (2+). Appetite was adequate but unable to eat due to flatulence and heaviness of abdomen after eating. Thirst was adequate with approximately 2 litres per day for cold water $(1+)$. Desire for cold things $(1+)$ and sour things (1+) Aversion to fatty food (1+). Stools were unsatisfactory and hard. Sleep was unrefreshing with vivid dreams often. Profuse non offensive perspiration on palms and soles.

\section{Mental generals}

Irritable on slightest things, prefers solitude and consolation aggravates.

On Breast examination, a solitary soft, tender, mobile mass of approximately $1 \times 0.5 \mathrm{~cm}$ in size was felt in left lower quadrant of the left breast. Overlying skin was normal in colour and temperature. No discharge from nipples. Axillary lymph nodes were not enlarged.

The sonographic report on 1st December, 2015 revealed a hypoechoic well defined oval shaped SOL of diameter $0.87 \times 0.43 \mathrm{~cm}$ in size in left breast at 30 'clock position beside the nipple, suggesting fibroadenoma.

Since there was no family history of carcinoma, the sonography was repeated after 3 months of treatment according to the guidelines ${ }^{[1]}$.

\section{Therapeutic intervention}

On the first visit, based on the modalities of the presenting complaint i.e., pain in breast on motion and better by rest, tendency to flatulence, along with unsatisfactory hard stools, irritable temperament, and desire for solitude, Bryonia 200, three doses was prescribed followed by placebo for 15 days, along with dietary advice for correcting the bowel habits. In subsequent follow-ups, improvement could not follow to a remarkable extent, so repertorisation was done after analysis and evaluation of the symptoms, using Kent's repertory.

\section{Totality of symptoms}

- Pain left breast, aggravation from motion, better by rest $(+++)$

- Unsatisfactory, hard stools $(++)$

- Flatulence after eating (+++)

- Desire for cold things and sour things $(++)$

- Aversion to fatty food (+)

- Thermal reaction chilly (++)

Repertorisation was done using Hompath classic software [19].

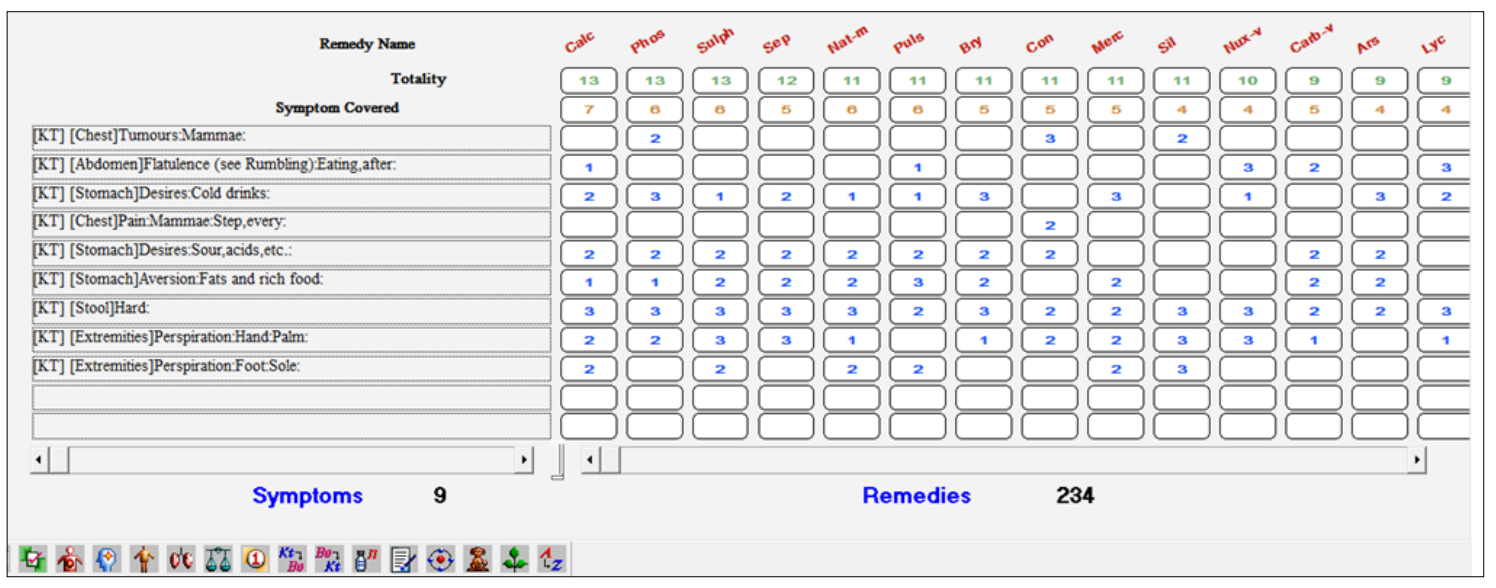

Fig 2: Repertorisation chart (using Hompath Classic software, version 10) 


\section{Repertorial result}

Calc carb (13/7), Phos (13/6), Sulph (13/6), sepia (12/5). In concordance chapter of BTPB, under Bryonia, related medicines under the heading 'gland', Phosphorus was given in the first grade. Phosphorus $1 \mathrm{M}$ was prescribed with placebo for one month. After three months, the ultrasonography was repeated. On 19th March 2019, the report showed no abnormality in both the breast.

\section{Timeline}

\begin{tabular}{|c|c|c|}
\hline Date & Follow-up & Prescription \\
\hline $18^{\text {th }}$ Dec, 2018 & $\begin{array}{l}\text { Pain in breast better, flatulency better, stools- same, no } \\
\text { new complaint }\end{array}$ & Bryonia 200/one dose Placebo/one month \\
\hline $10^{\text {th }}$ Jan, 2019 & $\begin{array}{l}\text { No improvement in pain in breast, Flatulence was better, } \\
\text { stool- same }\end{array}$ & Bryonia 1M/one dose Placebo/15 days \\
\hline $25^{\text {th }}$ Jan, 2019 & $\begin{array}{l}\text { No improvement in pain in breast, Flatulency same, } \\
\text { stool- same }\end{array}$ & Placebo/15 days \\
\hline $10^{\text {th }} \mathrm{Feb}$ & No improvement, General condition- same & Phosphorus 1M/one dose Placebo/one month \\
\hline 5 March, 2019 & $\begin{array}{l}\text { Pain-better, flatulency-better, stools- Normal, } \\
\text { satisfactory }\end{array}$ & Placebo/one month \\
\hline $19^{\text {th }}$ March 2019 & Pain breast- improved, no flatulency, stool- satisfactory & Placebo/one month \\
\hline
\end{tabular}

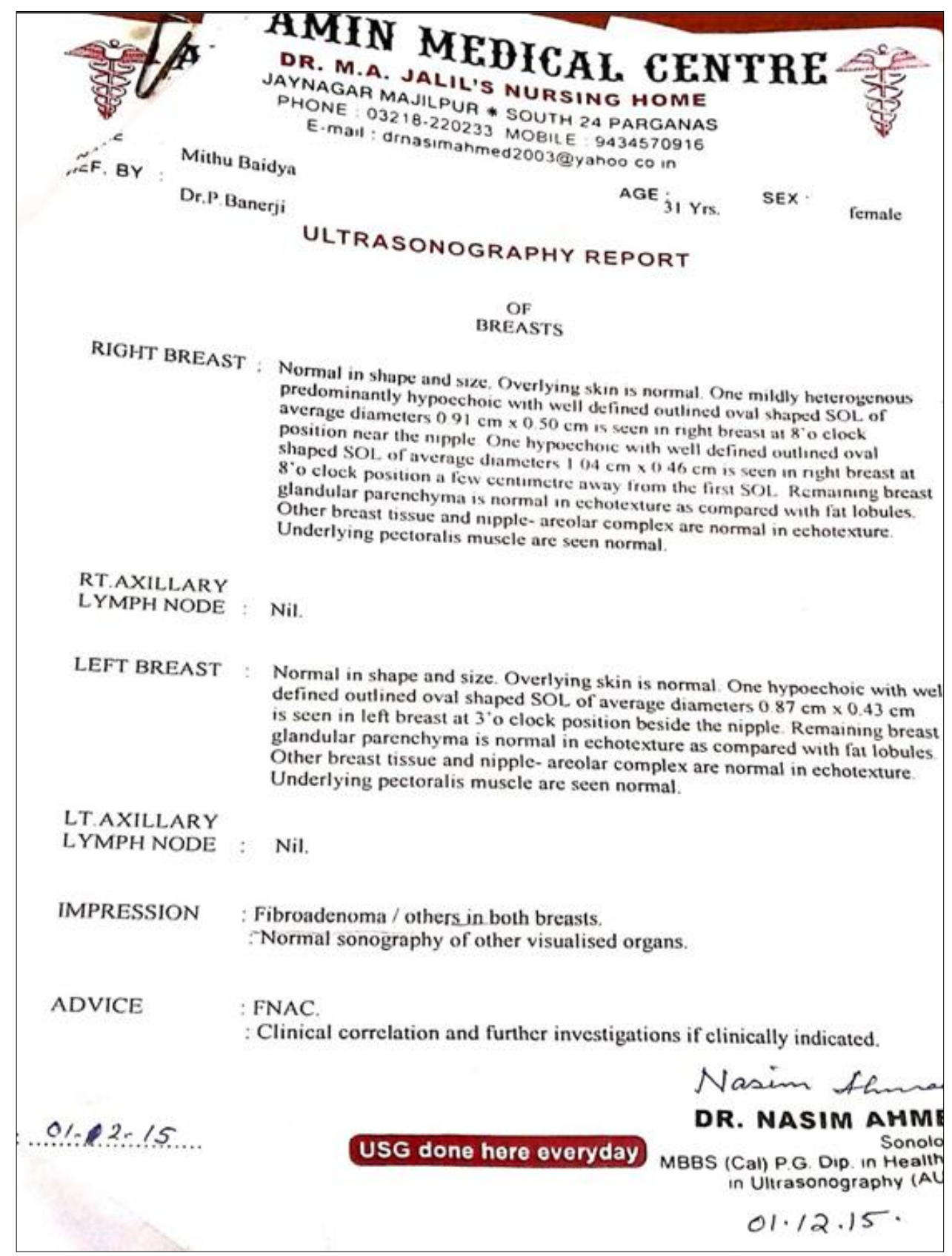

Fig 3: Ultrasound as on 1/12/2015 revealing hypoechoic shadow in left breast 


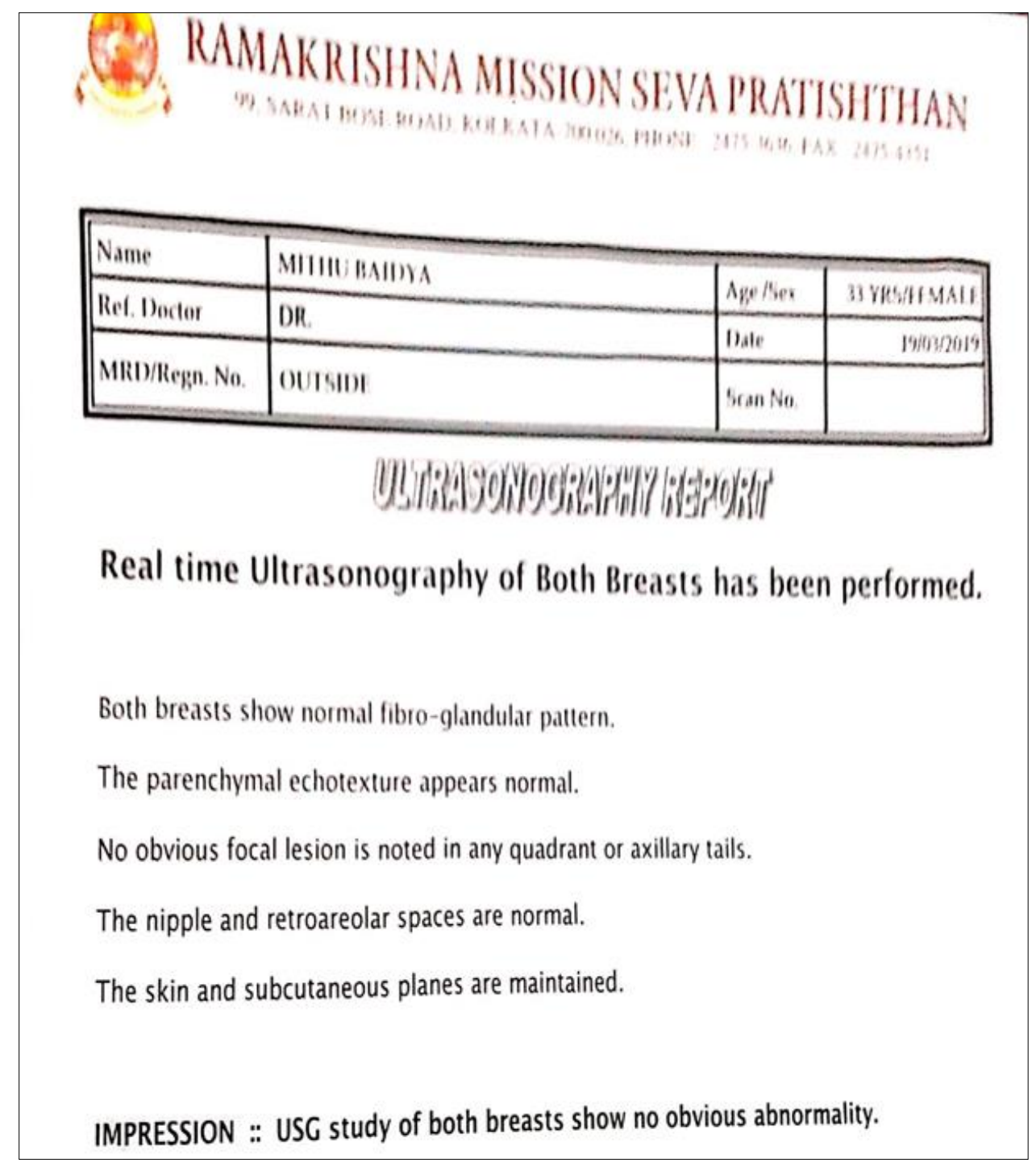

Fig 4: Ultrasound on $19^{\text {th }}$ March 2019 revealing no abnormality in both the breast

\section{Discussion}

A case of fibroadenoma breast diagnosed on ultrasonography was managed by Bryonia, based on presenting complaint and its modalities. After initial relief, the medicine stopped acting effectively, even after increasing the potency, so a follow- up remedy was selected using concordance chapter of Boenninghausen's therapeutic pocket book 20 which consists of 142 remedies with their relations mentioned under 12 subheadings. The utility of this chapter comes after the first prescription has acted and the case now requires another deep acting remedy in relation with the previous one. In this case, after Bryonia, for completion of the cure, another remedy Phosphorus (in relation to Bryonia), was found under the heading 'glands'. Since Phosphorus was also one of the first four remedies after repertorisation of the totality of the symptoms, the medicine was prescribed with marked improvement and cure of the case.

This case directs the importance of an effective follow-up which should be conscientiously dealt with, using relationships of remedies mentioned in different source books like BTPB and Boenninghausen's characteristics and repertory by C.M. Boger ${ }^{[21]}$. Fibroadenoma breast being a chronic benign lesion requires constitutional treatment and should be carefully monitored. Ultrasound and core needle biopsy should be repeated every 3-4 months if there is no malignancy ${ }^{[1]}$.

\section{Conclusion}

A case of benign solitary mass in the breast, diagnosed as fibroadenoma, on ultrasonography was effectively cured through homoeopathic medicine Bryonia, followed by Phosphorus. Since the size of the mass was small $(0.84 \times 0.43 \mathrm{~cm})$, the treatment lasted for four months after which ultrasound was repeated which revealed no abnormality in the breast. This case suggests that homoeopathy can prove to have a positive role in not only symptomatic relief but also a complete cure in fibroadenoma breast.

\section{References}

1. Armando Giuliano E, Sara Hurvitz A. 'Breast disorders', in Maxine A., Papadakis, Stephen J Mc Phee (ed.) Current medical diagnostics and therapeutics. New York: Mc Graw Hill 2019, 751-760.

2. Chandraja CV, Sathish Kumar. 'A case of left mammary fibroeodenoma successfully cured by homoeopathic therapy', Research on Chronic Diseases 2018;2(2):49-54.

https://www.openaccessjournals.com/articles/a-case-ofleft-mammary- fibroadenoma-successfully-cured-byhomoeopathic-therapy.pdf 
3. Suraiya Parveen. 'Individualized homoeopathic treatment of breast fibroadenoma: A case report', Research on Chronic Diseases 2018;12(2):46-52. 10.4103/ijrh.ijrh_1_16

4. Sainsbury Richard. The Breast and Endocrine. Norman S. Williams (ed). Bailey and Love's Short Practice of surgery, 27th ed. New York: CRC Press 2008, P827.

5. Das Somen. The Breast. (ed). A Concise Textbook of Surgery, 4th ed. Calcutta: S Das 2006, 691- 738.

6. Kundu Arup Kumar. Lymphoma. (ed). Bedside Clinics in Medicine, 7th ed. Kolkata: Kaustuv Paul \& Shibaji Bose 2017, 245.

7. Fabio Levi, Lalao Rnadimrison et al. 'Incidence of breast cancer in women with fibroadenoma', International Journal of Cancer 1994.

https://onlinelibrary.wiley.com/doi/abs/10.1002/ijc.291 0570512 (Accessed: 15 May, 2020).

8. Maleeha Ajmal, Kelly Van Fossen. Breast Fibroadenoma 2019.

https://www.ncbi.nlm.nih.gov/books/NBK535345/

9. Nassar Aziza. Complex Fibroadenoma and Breast Cancer Risk: A Mayo Clinic Benign Breast Disease Cohort Study. Breast Cancer Research and Treatment 2015;153(2). 10.1055/s-0033- 1343997

10. Wendy $\mathrm{K} \mathrm{Ng}$ et al. Juvenile fibroadenoma of the breast: Treatment and literature review. Can J Plast Surg 2011;19 (3). 10.1177/229255031101900308

11. Hille Betz U. Treatment of Giant Fibroadenoma in Young Women: Results after Tumor Excision without Reconstructive Surgery. Geburtshilfe Frauenheilkd 2015;75(9). https://www.ncbi.nlm.nih.gov/pmc/articles/PMC45966 98

12. Mishra Shashi Prakash. Phyllodes Tumor of Breast: A Review Article. ISRN Surgery 2013, 361469. Reddy ES, Sharma PK, Raj PP. A clinical study on effect of Plantago in gingivitis by assessing bleeding and plaque index. Indian Journal of Research in Homoeopathy 2018;12(3):132. 10.1155/2013/361469

13. Fornage BD, Lorigan JG, Andry E. 'Fibroadenoma of the breast: sonographic appearance', Radiological Society of North America (RSNA) 1989;172(3). https://doi.org/10.1148/radiology.172.3.2549564

14. Hani Makky Al Salam. Fibroadenoma of the Breast. https://radiopaedia.org/cases/fibroadenoma-of-thebreast-1

15. Sandhya Pruthi. Nonsurgical Management of Fibroadenoma and Virginal Breast Hypertrophy. Semin Plast Surg 2013;27(1). 10.1055/s-0033-1343997

16. Boukje Hermans JE. Quality of life after breast reduction. Can J Plast Surg 2005;55(3). 10.1097/01.sap.0000171444.79737.70

17. Shukla Purnima et al. Homoeopathic Management of Breast Fibroadenoma - An Open Label, Single Arm, Observational Trial. Homoeopathic Links 2020;33(2). https://www.thieme-

connect.com/products/ejournals/abstract/10.1055/s0040-1712479

18. Abdelgawad Iman A et al. Significance of serum levels of Vitamin D and some related minerals in breast cancer patients. International Journal of Clinical and Experimental Pathology 2015;8(4). https://www.ncbi.nlm.nih.gov/pmc/articles/PMC44669 82.
19. Shah J, Hompath J. Classic. Tata Consultancy Services 2005.

20. Clemens Maria Frans Von Boenninghausen. Boenninghausen's therapeutic pocket book for homoeopathic physicians: to use at the bedside and in the study of the materia medica, 2 edn., Delhi: B. Jain Publisher 2009.

21. Cyrus Maxwell Boger. Boger Boenninghausen's characteristics and Repertory, 2 edn., Delhi: B. Jain Publisher 2009. 